\title{
Surgical Treatment of Thyrotoxicosis in Children and Adolescents
}

By Norman W. Thompson, Ernest L. Dunn, John E. Freitas, James C. Sisson, Arnold G. Coran, and Ronald H. Nishiyama

- Forty-one children and adolescents had thyroidectomies for Grave's disease during an 8 yr period. Twenty parients became euthyroid within a short period after treatment with antithyroid drugs and had operations with minimal disruption of their lives. Antithyroid drugs were administered to 20 patients for a longer period of time as a primary form of treatment for Grave's disease. Complications resulting from drug toxicity, poor cooperation by patients, and persistent goiters were indications for thyroidectomies in this group. Permanent remissions, after prolonged antithyroid drug therapy, are rare in children. Because the treatment is associated with significant morbidity, this form of therapy is unacceptable in most cases. lodine-131 was given to 30 children or adolescents for Grave's disease during the same time period. lodine-131 is primarily indicated for patients who are resistant or allergic to antithyroid drugs, who have serious systemic diseases, or who have had previous thyroid operations. Hypothyroidism is an inevitable result of effective ${ }^{131}$ I ireatment of Grave's disease in children. Serious consequences from ${ }^{131}$ I therapy were not observed during the short period of follow-up. Subtotal thyroidectomy continues to be the preferred primary treatment for most patients with Grave's disease in childhood. Total thyroidectomy may be indicated for patients in the first decade of life. Hypothyroidism, which is easily managed in this age group, is the price paid for the prevention of recurrent Grave's disease. Early detection and treatment of hypothyroidism can be achieved only by a careful follow-up of all patients treated by less than total thyroidectomy for Grave's disease.

INDEX WORDS: Thyrotoxicosis; Grave's disease.

$\mathbf{F}$

ORTY-FIVE CHILDREN, 13 yr of age or younger, were treated for thyrotoxicosis at the University of Michigan Medical Center during the period from 1945 -1965. The results in this group were first reported in 1969.' It was then concluded that subtotal thyroidectomy was the operation of choice for these patients because of the low morbidity, early remission and low incidence of hypothyroidism.

This report updates our data by including 41 more children who were treated surgically during the past $8 \mathrm{yr}, 1969-1976$, and an additional 30 children treated with radioactive iodine $\left({ }^{131} \mathrm{I}\right)$. This review was done to reevaluate the role of subtotal thyroidectomy in the management of thyrotoxicosis in children and adolescents.

From the Section of General Surgery, Department of Surgery, Section of Nuclear Medicine. Department of Internal Medicine, Section of Pediatric Surgery, Department of Surgery, Department of Pathology, University of Michigan Medical Center, Ann A rbor, Michigan.

Presented before the 8th Annual Meeting of the American Pediatric Surgical Association. Acapulco, Mexico, A pril 20-23, 1977.

Address reprint requests to Dr. Thompson, Rm. 7554. Outpatient Bldg., University Hospital. 1405 E. Ann St. Ann A rbor, Mich. 48109.

(6) 1977 by Grune \& Stratton, Inc. ISSN 0022-3468. 


\section{MATERIALS AND METHODS}

The clinical diagnosis of thyrotoxicosis was confirmed by determinations of serum triiodothyronine and serum thyroxine or protein-bound iodine in earlier cases. In a number of cases, scintiscans and $24 \mathrm{hr}$ uptakes of ${ }^{131} \mathrm{I}$ were obtained. Thyroidectomies were performed in 21 female and 20 male patients. The mean age was $13.3 \mathrm{yr}$, with a range of from $2-18 \mathrm{yr}$ of age. Thirty-eight patients were white, and three black. Seven children were $10 \mathrm{yr}$ of age or younger when the diagnosis of thyrotoxicosis was made and treatment begun.

The most common symptoms were nervousness, irritability, weight loss, and failure in school. The most common physical findings were exophthalmos, systolic hypertension, tachycardia, and weight loss. In 38 patients, the thyroid gland was diffusely enlarged, ranging from two to six times the size of a normal gland. Two patients had prominent solitary nodules in enlarged glands. One patient had a multinodular gland.

After the diagnosis of Grave's disease had been established, all patients were made euthyroid with either propylthiouracil or methimazole. Most patients were given Lugol's solution one to two weeks before the operation. However, during the last few years, propranolol was also given at the time antithyroid drug therapy was begun or for several weeks preoperatively. Iodine was omitted. There were 21 patients who had the operation at a time which was convenient for the family. This ranged from $6 \mathrm{wk}$ to 6 mo after antithyroid drugs were given.

Long term treatment with antithyroid drugs had been undertaken for 20 children. All of these patients were treated with the hope of avoiding an operation and treatment with radioactive iodine (Table 1). The time of treatment ranged from 3 mo to $3 \mathrm{yr}$. In seven patients, with and without goiters, operation was done to treat hyperthyroidism which recurred after a 2 yr course of treatment with propylthiouracil. In three, operations were done for cosmetic reasons, although the signs and symptoms of hyperthyroidism had been controlled. One operation was done because of concern about cancer when a scintiscan of the thyroid gland showed a solitary cold nodule. An $18 \mathrm{yr}$ old male had a subtotal thyroidectomy done because of failure to control atrial fibrillation by drug therapy. While taking methimazole for $6 \mathrm{mo}$, a $16 \mathrm{yr}$ old girl had three episodes of intrathyroidal hemorrhage which finally led to a thyroidectomy. A 12 yr old boy had emotional problems in school while taking propylthiouracil for one year and was advised to have a thyroidectomy. Two girls, 13 and $17 \mathrm{yr}$ of age, who were on antithyroid drugs for a year, were chronically absent from school and were poor students. They had subtotal thyroidectomies. A 9 yr old girl was unable to maintain a regular drug schedule despite attempts to closely supervise her treatment. A $16 \mathrm{yr}$ old boy, begun on propylthiouracil, developed hostility toward his parents and friends and a bizarre pattern of behavior. Two patients had less impressive complications. One patient found it impossible to adhere to a regular drug schedule and the other child required numerous adjustments of the dosage of her drug for $3 \mathrm{yr}$.

Thirty-four patients had bilateral subtotal thyroid lobectomies. A single patient had a total lobectomy on one side and a subtotal lobectomy on the contralateral side. Six patients had total thyroidectomies. When bilateral subtotal thyroidectomies were done, $95 \%-98^{\circ}$ of the thyroid gland was removed, and an estimated $1-2 \mathrm{~g}$ of thyroid tissue were left on both sides. The amount of thyroid tissue excised varied with the size and age of the patient and ranged from $30 \mathrm{~g}$ to more than $80 \mathrm{~g}$. The histologic sections of all of the thyroid glands were reviewed.

Table 1. Failures of Long-Term Antithyroid Drugs

\begin{tabular}{lcc}
\hline \multicolumn{1}{c}{ Indication for Thyroidectomy } & Number of Patients & Duration of Therapy \\
\hline Recurrence of thyrotoxicosis & 7 & $2 \mathrm{yr}$ \\
Persistent large goiter & 3 & $2 \mathrm{yr}$ \\
Inability to maintain drug schedule & 3 & $1-3 \mathrm{yr}$ \\
Failing in school work & 2 & $1 \mathrm{yr}$ \\
Severe emotional problems & 2 & $6 \mathrm{mo}-1 \mathrm{yr}$ \\
Palpable solitary, "cold" nodule & 1 & $1 \mathrm{yr}$ \\
Failure to control atrial fibrillation & 1 & $3 \mathrm{yr}$ \\
3 episodes of intrathyroidal hemorrhage & 1 & $6 \mathrm{mo}$ \\
Total & 20 &
\end{tabular}


Table 2. Radioactive lodine Therapy for Grave's Disease

\begin{tabular}{lcc}
\hline \multicolumn{1}{c}{ Indications } & Number of Patients & Age \\
\hline $\begin{array}{l}\text { Systemic Disease } \\
\text { asthma, Downs syndrome, }\end{array}$ & 5 & $9,10,16,17,18 \mathrm{yr}$ \\
ulcerative colitis, psychosis, & & \\
$\quad$ nephrotic syndrome & & \\
Failure to control with antithyroid drugs & 4 & $3,12,12,18 \mathrm{yr}$ \\
Severe antithyroid drug reaction & 6 & $6,10,13,15,16,16 \mathrm{yr}$ \\
Refused recommended thyroidectomy & 3 & $14,16,18 \mathrm{yr}$ \\
Recurrence of thyrotoxicosis after & 3 & $15,17,18 \mathrm{yr}$ \\
subtotal thyroidectomy & & \\
Selected as definitive treatment & & $15,16,17,18 \mathrm{yr}$ \\
after 1-2 yr of antithyroid drugs \\
after 2-8 mo antithyroid drugs
\end{tabular}

Thirty children were treated with ${ }^{131}$ I during the 8 yr period 1969 through 1976 (Table 2). The presence of hyperthyroidism was established by standard clinical and laboratory criteria. The thyroid gland ranged from $1 \frac{1}{2}$ to 15 times normal size. Grave's ophthatmopathy. Classes II and III (ATA criteria) was present in $43 \%$. The mean age at the time of initial ${ }^{\mathrm{L}} \mathrm{I} I$ therapy was 15.1 years with a range of 3-18 yr. Females predominated: 24 of 30 patients. Thyroidectomy was felt to be contraindicated in 21 patients (Table 2) while in the remaining 9. ${ }^{131} \mathrm{I}$ was selected because of the physician's or patient's preferences. Calculated doses of ${ }^{131}$ I were 60 $200 \mathrm{uCi} / \mathrm{g}$ of thyroid; the mean dose of single therapies was $9.9 \mathrm{mCi}$ with a range of $3-50.9$ $\mathrm{mCi}$ for cumulative doses. Five patients required more than one dose of ${ }^{131} \mathrm{I}$.

\section{RESULTS}

There were no significant intraoperative or early postoperative complications. Indirect laryngoscopy detected neither transient nor permanent injury to the recurrent laryngeal nerves. Two patients developed temporary hypocalcemia which responded to treatment with calcium and vitamin $\mathrm{D}_{2}$. Only one patient developed recurrent hyperthyroidism, two years after the removal of $95 \%$ of the thyroid gland. She was treated with radioactive iodine.

Twenty-three patients have been followed for 2 or more yr and nine, for $4-5$ yr. Fourteen patients, including the six who had total thyroidectomies, were operated upon within the last $2 \mathrm{yr}$.

Hypothyroidism, detected by examinations beginning at least three months after the operation and at yearly intervals, developed in 27 of 41 patients $(66 \%)$, including those treated by total thyroidectomies. Treatment with thyroid hormone, for most patients was initiated within the first year after the operation. Of the patients not receiving thyroid hormone, none have developed hypothyroidism after one year. The usual replacement dose of dessicated thyroid is $120 \mathrm{mg}$ per day.

The histologic sections of all thyroid glands showed the effects of treatment with propylthiouracil and Lugol's iodine. The glands were in all stages of involution. Some were nearly completely involuted and composed largely of follicles lined by a flat epithelium and well filled with colloid. Other were only partially involuted with a mixture of well-involuted areas with areas showing residual hyperplastic changes. The degree of lymphocytic infiltration of the thyroid gland was evaluated in each case but there was no correlation with the 
eventual development of hypothyroidism. One case had the classic changes of Hashimoto's disease with a marked degree of fibrosis and lymphocytic and plasmacytic infiltrates. There was extensive atrophy of follicular epithelium. The histologic changes were very suggestive of those found in the glands of patients with spontaneous myxedema.

One patient treated with ${ }^{131}$ I has been lost to follow-up and two patients have not been followed for sufficient time to assess the effects of therapy. Of the remaining 27 patients, $22(81.4 \%)$ had relief of their hyperthyroidism from the first dose of ${ }^{131} I$, while four required two doses, and one required three. Hyperthyroidism subsided in a mean time of $5.2 \mathrm{mo}$, a minimum of $2 \mathrm{mo}$, and a maximum of $18 \mathrm{mo}$. There has been no recurrence of hyperthyroidism to date. Progressive ophthalmopathy was not seen, but proptosis persisted in some patients. Associated with the elimination of hyperthyroidism by a single dose of ${ }^{131} \mathrm{I}$ was a prevalence of biochemical hypothyroidism of $51.8 \%(14 / 27) 6$ months after treatment. At the time of this report, hypothyroidism has been found in $74 \%$ $(20 / 27)$ over a mean follow-up period of 44.5 months. The high incidence of subsequent hypothyroidism appeared to be independent of the size of the initial treatment dose.

\section{DISCUSSION}

The controversy over the optimal treatment of Grave's disease in children and adolescents has not been resolved. Subtotal thyroidectomy is commonly recommended, but advocates of long term antithyroid drugs or radioactive iodine claim comparable results. ${ }^{2-19}$ More recently, surgeons have advocated total thyroidectomy because it eliminates recurrences, and with prompt and conscientious administration of thyroid hormone the development of hypothyroidism is avoided. ${ }^{20-22}$

Treatment with antithyroid drugs has the disadvantage of requiring close supervision during a long period of time. In our experience, it is difficult to maintain children on propylthiouracil or methimazole even when the patient and parents are cooperative. Furthermore, permanent remission, after one to two years of therapy, has been unusual in adolescents and rare in children. In both groups, goiters have persisted and have been problems for the patient and the parents. Another dilemma is the development of allergic or toxic reactions to antithyroid drugs. Such patients are then referred for surgical treatment while still toxic, either due to failure to control the disease or a relapse after withdrawal of the drugs. Safe preparation of these patients for an operation is difficult. Iodine and or propranolol may alleviate the symptoms, but the risk of developing thyroid storm after an operation is increased in such cases. Therefore, during the past decade, the majority of such patients have been treated with ${ }^{131} \mathrm{I}$. Pediatrician and surgeons have agreed that this is the best form of therapy.

How effective are antithyroid drugs in controlling thyrotoxicosis in children and how often does a permanent remission result from their long term use? In our experience, only 4 of 71 patients $(5.6 \%)$ were resistant to treatment with either methimazole or propylthiouracil. Toxic and allergic reactions in six occurred after these patients were controlled well. The antithyroid drugs have 
allowed patients to have thyroidectomies while in a euthyroid state. Their use has virtually eliminated the postoperative complication of thyroid storm. Earlier investigators optimistically predicted that the long term use of antithyroid drugs in most patients with Grave's disease would result in permanent remissions. In 1953, Solomon found that $55 \%$ of adult patients with Grave's disease remained in remission for $4 \mathrm{yr}$ after a course of antithyroid drugs of 6 mo to $1 \mathrm{yr} .{ }^{24}$ However, in the next two decades, other investigators reported a decreasing frequency of remissions even when antithyroid drugs were given for two years. Hayles and Chaves-Carballo found only 4 of 16 patients less than 15 yr of age to be in remission 2 yr after a long term course of antithyroid drugs. ${ }^{6}$ Data from major series published since 1954 show that among 99 children who were treated with antithyroid drugs and followed up for at least $2 \mathrm{yr}$ after completion of therapy, only 27 were not hyperthyroid. ${ }^{12}$ In general, these results are considered unacceptable. Wartofsky recently suggested that the low rates of remission may be caused by an increased dietary intake of iodine and seriously questioned the long term use of antithyroid drugs. ${ }^{23}$ In his series remissions after long term treatment occurred in only $11 \%$ of his patients; none of these were under 21 yr of age. In our previous report, 10 of 64 children $(16 \%)$ had prolonged remissions, and none of them were under $10 \mathrm{yr}$ of age. The conclusion at that time, was that subtotal thyroidectomy should be done in the pediatric patient with Grave's disease unless contraindicated because of other concurrent disease or uncontrolled thyrotoxicosis. Neverless, nearly $50 \%$ of patients having thyroidectomies or ${ }^{131} \mathrm{I}$ in the present review had received antithyroid drugs for 8 mo or longer in the hope of inducing a permanent remission. Only 21 patients became promptly euthyroid and had an operation. Three of the 20 patients on a prolonged course of antithyroid drugs had no difficulty controlling their thyrotoxicosis. However, their thyroid glands continued to enlarge and because of problems of pressure symptoms and for cosmetic reasons, elective thyroidectomies were done. Seventeen patients had unacceptable results with drug treatment. In contrast, there were no complications in the 21 patients who were given antithyroid drugs immediately after the diagnosis of Grave's disease was confirmed, became euthyroid and had thyroidectomies. The time required to achieve this ranged from $6 \mathrm{wk}$ to $3 \mathrm{mo}$.

Those who advocate ${ }^{131} I$ in the treatment of childhood thyrotoxicosis emphasize the ease with which it may be given, the low cost and its safety. ${ }^{15-19}$ Radioiodine therapy is an effective means of terminating the hyperthyroid state in children within a period of months. We have been reluctant, however, to utilize this form of therapy in children, except when alternative forms of treatment were unacceptable because of the theoretical risks associated with radioactive iodine, such as the development of leukemia, carcinoma of the thyroid gland, the insidious development of hypothyroidism, and induction of genetic changes. The magnitude of the risk, when ${ }^{131} I$ is used to treat Grave's disease during childhood, is unknown. ${ }^{25}$ Although its use is restricted in many hospitals, there are several where radioiodine is the treatment of choice for Grave's disease in children and some data is being accumulated. None of the $291 \mathrm{pa}$ tients reported in the English literature as having received radioiodine for hyperthyroidism when aged 18 or younger have developed leukemia or in- 
fertility nor have their progeny exhibited more congenital abnormalities than expected by chance. ${ }^{17}$ Thyroid carcinoma was discovered in two children whose hyperthyroidism was barely controlled by small doses of ${ }^{131} \mathrm{I}$. One of these developed thyroid carcinoma within 27 mo of ${ }^{131} I$ therapy, which suggests that the carcinoma was already present at the time of radioiodine therapy. ${ }^{26}$ The other child received three small doses of ${ }^{131} \mathrm{I}$ over a $4 \mathrm{yr}$ period and then, $4 \mathrm{yr}$ later, underwent a subtotal thyroidectomy for recurrent nodular goiter. ${ }^{27} \mathrm{Mul}$ tiple benign adenomas and one invasive "adenoma" of unknown size were found. The later child's cancer may have been prevented by destroying more thyroid gland with larger doses of ${ }^{131} I$. The absence of cancer in other children treated with radioiodine may be attributable to the use of larger doses of ${ }^{131} I$ which prevent thyroid cell replication. Further observation will be necessary to more firmly establish the safety of ${ }^{131} I$ therapy in children. In our hospital, the policy is to give ${ }^{131} \mathrm{I}$ to patients $18 \mathrm{yr}$ of age or younger only when other modes of treatment are contraindicated. We were surprised to find that 30 children and adolescents had been treated with ${ }^{131} \mathrm{I}$ during $8 \mathrm{yr}$ period covered by this review. Analysis of those cases shows that five had scrious systemic diseases. Each patient had a protracted trial of antithyroid drugs with unsatisfactory results before ${ }^{131}$ I was given. Ten patients were still toxic after a protracted period of treatment with antithyroid drugs. Four were never fully controlled by increasing doses of either methimazole or propylthiouracil, and six developed allergic or toxic reactions to the drugs. These patients had been euthyroid from several months to $3 \mathrm{yr}$. In retrospect, each of these patients could have had a thyroidectomy when they were euthyroid. Three patients with recurrent thyrotoxicosis after subtotal thyroidectomies were treated with ${ }^{131}$ I. Two of these patients had operations elsewhere and were referred for treatment with ${ }^{131}$ I after antithyroid drugs failed. The reluctance of three patients to have thyroidectomies resulted in the giving of ${ }^{131} \mathrm{I}$. Nine patients were given ${ }^{131}$ I after treatment with antithyroid drugs for 2 mo to 2 yr. These patients, who were 10-18 yr of age, had no apparent contraindications for operations.

Hypothyroidism has been detected in $74 \%$ of the 27 patients treated with ${ }^{131}$ I and followed for sufficient time to assess the effects of therapy. It is anticipated that a decrease in dose would yield a lower prevalence of hypothyroidism after $6 \mathrm{mo}$, at the expense of persistent hyperthyroidism in many of the children. Only $81 \%$ of these patients were relieved of their hyperthyroidism with one dose of ${ }^{131} \mathrm{I}$. The true incidence of permanent hypothyroidism is possibly less than $74 \%$. However, in order to prevent physical growth retardation, replacement therapy was initiated as soon as biochemical evidence of hypothyroidism occurred. We prefer to continue hormone therapy in all such patients either as essential replacement or as therapy to prevent regrowth of goiter from residual tissue. The development of hypothyroidism should be anticipated in virtually all children who receive sufficient ${ }^{131}$ I to relieve thyrotoxicosis.

We still believe that until a larger group of children are followed for a longer period of time, the use of ${ }^{131} \mathrm{I}$ in children should be restricted to patients considered unsuitable for other forms of treatment.

The need for prompt and effective treatment of the thyrotoxicosis in the pediatric age group is obvious. These patients are in the midst of their physical 
and emotional development. It is imperative that they be euthyroid during their years of growth and development. From our review, it is apparent that poorly treated thyrotoxicosis affected the learning ability and personality of these patients. Prolonged treatment with antithyroid drugs is unacceptable for children unless they can be easily controlled and maintained on the drugs without constant supervision. Surgical treatment permanently restored these children to a euthyroid state with minimal disruption of their lives. Subtotal thyroidectomy is the preferred operation, providing it is done with no mortality and minimal morbidity.

One patient out of $40(2.5 \%)$ developed recurrent hyperthyroidism after a primary thyroidectomy. This occurred $2 \mathrm{yr}$ after a standard subtotal thyroidectomy with no more than two or three grams of thyroid tissue left. This $9 \mathrm{yr}$ old girl was treated with ${ }^{131} \mathrm{I}$. A second patient had a subtotal thyroidectomy the year before the period of review, at $2 \mathrm{yr}$ of age. Although only one gram of thyroid remnant was left on each side, rapid regeneration occurred, and a goiter was again palpable. At his second operation, $40 \mathrm{~g}$ of thyroid tissue was removed, and a total thyroidectomy was performed. This patient was the only child to have a recurrence in the group of 45 patients previously reported. We agree that treatment of recurrences after thyroidectomy should be with ${ }^{13 i} I$ because of the high rate of complications reported with secondary thyroidectomies. ${ }^{14,28,29,30}$ This patient's age and the large goiter were the factors considered in doing a carefully performed total thyroidectomy. These are the only two children with recurrent thyrotoxicosis $(2.3 \%)$ after thyroidectomy during the past $30 \mathrm{yr}$ among 85 patients. During the period of this review, our surgical philosophy has been to err toward removing too much rather than too little thyroid tissue to decrease the possibility of recurrent hyperthyroidism, a much more difficult problem to treat than hypothyroidism. A larger thyroid remnant results in a greater number of euthyroid patients but also increases the incidence of recurrent disease. When remnants are greater than $4 \mathrm{~g}$, the incidence of recurrence may be as high as $4 \%{ }^{\circ} \cdot{ }^{9,12,14,31-35}$ The evidence shows that the two traditional goals of subtotal thyroidectomy for Grave's disease, permanent cure and prevention of hypothyroidism, are mutually exclusive. ${ }^{9}$ We agree with Wesley and his colleagues who believe that the primary goal of the operation must be to remove enough thyroid tissue to insure that the patient will not continue to have hyperthyroidism. The surgeon should not be influenced by the possibility of postoperative hypothyroidism. ${ }^{14}$

Altman has suggested that total thyroidectomy may be an alternative procedure in selected pediatric cases. ${ }^{20}$ In advocating total thyroidectomy, he emphasizes that Grave's disease is not "cured" by subtotal removal of the thyroid gland. The remnant is still subject to the stimulation that existed before the operation. He states that determination of the size of the remnant is an imprecise and arbitrary decision in each case. Our experience confirms Altman's observations in that two recurrences were in paticnts after a standard subtotal thyroidectomy when remnants of thyroid tissue estimated to be less than $4 \mathrm{~g}$ were left. The risk of rapid regeneration of thyroid remnants is greatest in patients less than $10 \mathrm{yr}$ of age. For this reason, we now consider total or near-total thyroidectomies in such patients. Perzik, on the other hand, recommends that 
total thyroidectomy be done in all patients with Grave's disease. ${ }^{21,22}$ There were no deaths, no recurrences, no permanent recurrent laryngeal nerve injuries and only one patient, in his series of 326 patients, developed permanent hypoparathyroidism. None of his patients developed or had progression of existing ophthalmopathy. The operations also eliminated occult or microscopic cancers which were found in $7 \%$ of his patients. All patients received exogenous thyroid hormone permanently, a procedure that does not differ from that used after many subtotal thyroidectomies.

We helieve that total thyroidectomy must be performed with no more morbidity than would occur after a subtotal or near-total thyroidectomy, if it is to be done to eliminate all recurrences of Grave's disease. ${ }^{36}$ This goal is unlikely to be achieved by most surgeons unless they are very experienced and skillful in performing thyroid operations. We believe that recurrence is unlikely to occur in patients over $15 \mathrm{yr}$ of age following a subtotal thyroidectomy leaving a small remnant $(2-4 \mathrm{~g})$. Many of these patients will not require replacement with thyroid hormone. Because of the good results in this age group after subtotal thyroidectomy, we do not feel that total thyroidectomy is routinely justified.

Hypothyroidism, in our group of patients, developed during the first year after operation. This observation agrees with that of Olsen and colleagues who found that $88 \%$ of patients who became hypothyroid after subtotal thyroidectomies were diagnosed within the first 6 mo. ${ }^{10}$ The high incidence of hypothyroidism after subtotal thyroidectomy $(60 \%)$ is attributed to the small remnant of thyroid tissue left and the careful follow-up examinations specifically designed to detect mild hypothyroidism. This high incidence markedly contrasts with the $5 \%$ reported in our patients by Tank and associates in 1969.' In a partial follow-up of that group, however, additional patients have been found to be hypothyroid.

A clinical diagnosis of mild hypothyroidism is difficult to establish in the pediatric patient. These patients often appear normal. In 1968, determinations of serum levels of $T_{3}, T_{4}$, and TSH were not used, and the criteria for the diagnosis of hypothyroidism, used in the present study, were not available. A careful follow-up of these patients is important. The incipient development of hypothyroidism during a critical period of growth and development must be prevented. We have had no difficulty in treating hypothyroidism in the pediatric patient and do not consider its occurrence as a factor in our selection of treatment for Grave's disease.

\section{REFERENCES}

1. Tank ES, Bacon GE, Lowrey GH: Surgical management of thyrotoxicosis in children. J Pediatr Surg 4:142-147, 1969

2. Bacon GE, Lowrey GH: Experience with surgical treatment of thyrotoxicosis in children. J Pediatr 67:1-6, 1965

3. Barnes HW, Gann DS: Choosing thyroidectomy in hyperthyroidism. Surg Clin North Am 54:289-307, 1974

4. Block MA: Surgery vs radioactive iodine for hyperthyroidism. Surg Gynec Obstet 125: 1083-1084, 1967

5. Caswell HT, Maier WP: Results of surgi- cal treatment for hyperthyroidism. Surg Gynec Obstet 134:218-220, 1972

6. Hayles AB, Chaves-Carballo E: Exophthalmic goiter in children: Therapeutic trial with antithyroid drugs. Mayo Clin Proc 40:889, 1965

7. Hayles AB, Enrique C, McConahey WM: Treatment of hyperthyroidism in children. Mayo Clin Proc 42:216, 1967

8. Gough AL, Neill RW: Partial thyroidectomy for thyrotoxicosis. Br J Surg 61:939942,1974

9. Hedley AJ, Michie W, Duncan T, et al: 
Effect of remnant size on the outcome of subtotal thyroidectomy for thyrotoxicosis. $\mathrm{Br} \mathrm{J}$ Surg 59:559-563, 1972

10. Olsen WR, Nishiyama RH, Grater LW: Thyroidectomy for hyperthyroidism. Arch Surg 101:175-180,1970

11. Root WW, Bongiovanni AA. Harvie FF, et al: Treatment of juvenile thyrotoxicosis. J Pediatr 63:402, 1963

12. Sanfelippo PM, Beahrs OH. Hayles AB: Indications for thyroidectomy in the pediatric patient. Am J Surg 122:472-474, 1971

13. Schwartz DL, Gann DS, Haller JA: Endocrine surgery in children. Surg Clin North Am 54:363. 385, 1974

14. Wesley JR, Buckingham B, Gahr JA, et al: Surgical treatment of hyperthyroidism in children. Surg Gynec Obstet 145:343-346, 1977

15. Cevallos JL, Hagen GA, Maloof F, et al: Low-dosage ${ }^{131} I$ therapy of thyrotoxicosis (diffuse goiters). A 5-year follow-up study. N Engl J Med 290:141-143, 1974

16. Hayek A, Chapman EM, Crawford JD: Long term results of treatment of thyrotoxicosis in children and adolescents with radioactive iodine. N Engl J Med 283:949-953, 1970

17. Safa AM, Schumacher $P$, RodriguiezAntunez A: Long term follow-up results in children and adolescents treated with radioactive iodine $\left({ }^{131}\right.$ I) for hyperthyroidism. N Engl J Med 292:167-205, 1975

18. Starr P, Jaffe HL, Oettinger L Jr: Late results of ${ }^{131}$ I treatment of hyperthyroidism in 73 children and adolescents. J. Nucl Med 5:81. 1964

19. Starr P, Jaffe HL, Oettinger L Jr: Later results of ${ }^{131}$ I treatment of hyperthyroidism in 73 children and adolescents: 1967 follow-up. J Nucl Med 10:586-590, 1969

20. Altman PR: Total thyroidectomy for the treatment of Grave's disease in children. J Pediatr Surg 8:295-300, 1973

21. Perzik SL: Place of total thyroidectomy in the management of 900 patients with thyroid disease. Am J Surg 132:480-483, 1976

22. Perzik SL: Total thyroidectomy in Grave's disease in children. J Pediatr Surg 11 19l-194, 1976

23. Wartofsky L: Low remission after ther- apy for Grave's disease. JAMA 226:1083 1088,1973

24. Solomon DH: Prognosis of hyperthyroidism treated by antithyroid drugs. JAMA 152:201-205, 1953

25. Braverman LE: Consequences of thyroid radiation in children. N Engl J Med 292:204 205,1975

26. Dobyms BM, Sheline GE, Workman JB, et al: Malignant and benign neoplasms of the thyroid in patients treated for hyperthyroidism: A report of the cooperative thyrotoxicosis therapy follow-up study. J Clin Endocrinol Metab 38:976-998, 1974

27. Karlan MS, Pollock WF, Snyder WH $\mathrm{Jr}$ : Carcinoma of the thyroid following treatment of hyperthyroidism with radioactive iodine. Calif Med 101:196 199, 1964

28. Sheline GE, Lindsay S, Bell HG: Occurrence of thyroid nodules in children following therapy with radioiodine for hyperthyroidism. J Clin Endocrinol 19:127-137, 1959

29. Thompson NW, Olsen WR, Holfman G: Continuing development of the technique of thyroidectomy. Surgery 73:913-928, 1973

30. Beahrs $O H$, Sakuisky SB: Surgical thyroidectomy in the management of exophthalmic goiter. Arch Surg 96:512 516, 1968

31. Taylor GW. Painter NS: Size of the thyroid remnant in partial thyroidectomy for toxic goiter. Lancet 1:287-289, 1962

32. Michie W, Pegg CAS, Bewsher PD: Prediction of hypothyroidism after partial thyroidectomy for thyrotoxicosis. Br Med J I: 13-17, 1972

33. McNeill AD, Thomson JA: Long term follow-up of surgically treated thyrotoxic patients. Br Med J 3:643-646, 1968

34. Roy AD, Allan J. Harden R: follow-up of thyrotoxic patients treated by partial thyroidectomy. Lancet 2:684 688, 1967

35. Young $H B$, MacLeod $N$ : Fate and function of the thyroid remnant. A surgical and radioactive iodine study. $\mathrm{Br} \mathrm{J}$ Surg 59:726 731,1972

36. Thompson NW, Olsen WR, Hoffman GL: Continuing development of the technique of thyroidectomy. Surgery 73:913 927, 1973

\section{Discussion}

J. Weitzman (Los Angeles): In the early part of this year we completed a paper dealing with 43 patients who had subtotal thyroidectomy for thyrotoxicosis. Our results were the same as the series presented by Dr. Thompson, including a $65^{\circ}{ }^{\circ}$ incidence of hypothyroidism. Motivated by the hope of convincing other pediatric endocrinologists to believe. as the endocrinologists at 
Children's Hospital in Los Angeles believe, that subtotal thyroidectomy is the best treatment for hyperthyroidism in children, we submitted our manuscript to two pediatric journals. The following are some of the comments we received from the reviewers: "The main difference between the conclusions of these authors, including this reviewer, is the acceptability of $65^{\circ}$, hypothyroidism as a complication.... Committing a child to $50-70 \mathrm{yr}$ of thyroid replacement should not be taken so lightly. The problems of compliance with thyroid medication over a lifetime are not insignificant. Surgeons always minimize this at the same time that they maximize compliance problems of antithyroid medication." In response to our stating that we believe thyroidectomy is the best form of treatment for hyperthyroidism, one reviewer stated, "Some of the religious fervor for surgery should be toned down." Time does not allow me to repeat some of the other negative comments we received but we finally gave up; our paper is to appear in a leading surgery journal in a few months. A study of adults successfully treated medically has shown that $50^{\prime \prime}{ }_{0}$ of them eventually become hypothyroid. I am afraid that many pediatric endocrinologists will not be convinced regarding thyroidcctomy until it can be shown that many of the children who are successfully managed medically will become hypothyroid in the future.

A. de Lorimer (Los Angeles): I hope that Dr. Weitzman's editorial quotes appear in that 200 word discussion limit of the paper. There is no question that progressive hypothyroidism develops many years after radioiodine therapy. The longer one follows the series, the greater the incidence of hypothyroidism. It'll probably be equivalent to that of surgical resection.

J. Burringion (Chicago): How many surgeons here routinely begin thyroid replacement for all children after partial thyroidectomy"? The "dos" have it two to one. It is very appealing to start all of the children on replacement right away although the family may wonder, "why have the operation if they have to take pills anyway?" They might also miss a few days, notice no apparent ill effects and then not resume therapy.

J. Ternberg (St. Louis): It seems that more pediatric endocrinologists are agreeing with the Michigan and California groups. A member of our endocrine division has just reviewed the last 60 cases of hyperthyroidism treated here. The conclusions were similar, that is: (1) an unacceptably high incidence of complications results from the use of antithyroid drugs, and (2) surgical treatment gives good results. They aiso agree that the necessity of taking thyroid medication following thyroidectomy is innocuous, and should not be considered an unreasonable trade for the cure of hyperthyroidism. Indeed, in most cases, we start thyroid medication at the first follow-up visit. 1 would suggest that more positive results might come from publication by the pediatric endocrinologists rather than the pediatric surgeons, possibly as a collaborative effort by several institutions.

$N$. Thompson (Closing): I believe it is very important that we strive to have good results and avoid complications in order to mantain our position in the management of childhood thyrotoxicosis. Hypothyroidism occurs more frequently than we recognized in the past and cannot be avoided if recurrence is to be prevented. It should be emphasized that it can be detected during the first postoperative year and is as easily managed in children as it is in adults. Hypothyroidism of course, is frequent after ${ }^{131} \mathrm{I}$ administration and was detected in $50^{\circ}{ }^{\circ}$ of our patients within 6 mo and in $74^{\prime \prime}$, when the follow-up study was done at an average of 44 mo after therapy. We believe that if Grave's disease in children is treatcd successfully with ${ }^{131}$ I, hypothyroidism will ultimately result in nearly all cases. Unlike hypothyroidism following thyroidectomy. which always occurred within the first year, ${ }^{131}$ I-induced hypothyroidism may develop insidiously, years later, and go unrecognized.

In regards to total thyroidectomy. I would emphasize that I would be very reluctant to advocate doing this in young children unless done by surgeons highly experienced in the procedure as the potential for complications is greater. Particular emphasis should be made in future reports about the incidence of recurrence in patients under $10 \mathrm{yr}$ of age in order that we might really know whether total thyroidectomy should be considered the procedure of choice in that age group. The available data is insufficient to support a firm recommendation at this time. 